\title{
Relationship Between Level of Serum 25-Hydroxyvitamin D and Risk of Squamous Cell Carcinoma in an Iranian Population
}

\author{
Mahboobeh-Sadat Hosseini ${ }^{1}$, Fereshteh Salarvand ${ }^{2}$, Amir Houshang Ehsani ${ }^{2}$, Pedram \\ Noormohammadpour ${ }^{2}$, Shadi Azizzadeh ${ }^{2}$, Mohaddese Mousavi $^{3}$, Mona Morsali $^{3}$
}

1 Health Research Center, Lifestyle Institute, Baqiyatallah University of Medical Sciences, Tehran, Iran
2 Department of Dermatology, Razi Hospital, Tehran University of Medical Sciences, Tehran, Iran
3 School of Medicine, Tehran University of Medical Sciences, Tehran, Iran

Key words: skin cancer, squamous cell carcinoma, vitamin D, cancer epidemiology, supplements

Citation: Hosseini M-S, Salarvand F, Ehsani AH, Noormohammadpour P, Azizzadeh S, Mousavi M, Morsali M. Relationship between level of serum 25-hydroxyvitamin D and risk of squamous cell carcinoma in an Iranian population. Dermatol Pract Concept. 2019;9(4):278-282. DOI: https://doi.org/10.5826/dpc.0904a06

Accepted: June 17, 2019; Published: October 31, 2019

Copyright: (92019 Hosseini et al. This is an open-access article distributed under the terms of the Creative Commons Attribution License, which permits unrestricted use, distribution, and reproduction in any medium, provided the original author and source are credited.

Funding: None.

Competing interests: The authors have no conflicts of interest to disclose.

Authorship: All authors have contributed significantly to this publication.

Corresponding author: Fereshteh Salarvand, MD, Department of Dermatology, Razi Hospital, Tehran University of Medical Sciences, Razi Dermatology Hospital, Vahdat-e-Eslami Square, Tehran, Iran. Email: fsalarvand@razi.tums.ac.ir

ABSTRACT Background: The relationship between vitamin D and skin squamous cell carcinoma (SCC) is not well defined.

Objective: To investigate the relationship between vitamin D levels and the incidence of skin SCC for the first time in Iran.

Methods and Study Design: In this case-control study, 126 subjects were enrolled (63 in each group) out of referents to Razi Skin Hospital in Tehran in 2014. The risk factors for cancer gathered by self-reported questionnaires and blood samples were obtained to measure the level of 25 -hydroxyvitamin D. Multivariate logistic regression was used to neutralize the effect of confounding factors.

Results: Cases of SCC were more likely to be in men, older than 49 years and working in an outdoor environment, and with longtime exposure to sunlight and a personal history of skin cancers. Family history of skin cancer and of cigarette smoking were not significantly related to SCC. In the SCC and control groups, $69.8 \%$ and $31.7 \%$, respectively, had sufficient levels of vitamin $\mathrm{D}(\mathrm{P}<0.001)$. Mean level of 25 -hydroxyvitamin D was $40.99 \mathrm{ng} / \mathrm{mL}$ in the SCC group and $26.34 \mathrm{ng} / \mathrm{mL}$ in the control group $(\mathrm{P}<0.05)$. In the unadjusted model, the level of vitamin $\mathrm{D}$ as a continuous variable was positively related to SCC risk. In the adjusted model, vitamin D did not independently predict the likelihood of SCC.

Conclusion: Vitamin D level and SCC risk are directly related, although not in an independent fashion. Indeed, this relation is severely confounded by exposure to sunlight, which was evidenced by an increased vitamin D level in the people working outside and the higher prevalence of SCC in the same population. 


\section{Introduction}

Squamous cell carcinoma (SCC), after basal cell carcinoma, is the most common cancer in the white population and is associated with metastasis and considerable morbidity [1]. Over the past 10 to 30 years, its incidence in North America has increased approximately $50 \%$ to $200 \%$. Also, the incidence of this cancer is doubled by each 8 - to 10-degree decrease in latitude, and it approaches its highest rate near the equator. The age-specific incidence rate among Caucasians is 100 to 150 cases per 100,000 population, and this rate becomes 10 times higher among people older than 75 years [2].

Regarding cancer epidemiology, UV radiation from sunlight is the most important known risk factor for SCC of the skin. UVB is the main suspect (wavelength 290-320 nm), but UVA (wavelength 320-400 nm) may be accused as well [3]. UV radiation can cause mutations in the DNA of the skin cells, which is usually through the creation of thymine dimers in the p53 tumor suppressor gene. The inability of the immune system to repair the mutations leads to skin cancer [4]. Over the last half-century, changes in lifestyle have increased the exposure of populations to sunlight [3]. People with fair skin are most at risk. Occupational exposure to UV radiation is also known to have an effect.

One of the potential risk factors for SCC that has recently been brought to attention is vitamin $\mathrm{D}$ and its measurable serum marker 25-hydroxyvitamin D [25(OH)D] [5]. Eighty to ninety percent of vitamin $\mathrm{D}$ is produced in sunlight-exposed skin. This photobiosynthetic process is mainly mediated by UV rays [6], the same component of sunlight that is the leading risk factor for SCC. These interactions make a complicated relationship among vitamin $\mathrm{D}$, skin cancer, and UV rays. So far, there is no conclusive evidence in this regard [7].

On the one hand, many clinical, epidemiological, animal, and in vitro investigations have suggested that vitamin $\mathrm{D}$ and its metabolites have a risk-reducing impact on nonmelanoma skin cancer. This protective role comes from inhibition of the hedgehog signaling pathway (basal cell carcinoma) and modulation of p53-mediated DNA damage response (SCC) [3]. On the other hand, many authors believe in a direct relationship between vitamin $\mathrm{D}$ and skin cancers, mainly because vitamin $\mathrm{D}$ level is a reflection of individual exposure to sunlight UV rays [8-10]. Some believe the vitamin D endocrine system is also relevant in photocarcinogenesis through its receptor, VDR [11].

In summary, there is uncertainty about the association between vitamin D and skin cancer. So far, there is no available study in Iran, considering very high rates of vitamin $\mathrm{D}$ deficiency in this country $[12,13]$. Thus we conducted this study to help achieve a better understanding of the link between SCC risk and vitamin D in an Iranian population.

\section{Methods}

The subjects were selected from referrals to the day clinic of Razi Dermatologic Hospital (Tehran University of Medical Sciences, Tehran, Iran) in the year 2014. Based on previous studies [8] and available formulas for sample size calculation, to measure the difference between 2 means we entered 126 subjects into our study, 63 in each stem, considering the power of $80 \%$ and $\alpha=0.05$. Thus, in our case-control study, 63 patients who attended our hospital clinic with a new-onset dermal lesion compatible with SCC (determined by an expert dermatopathologist) were enrolled as the case group. Those with a history of childhood radiotherapy for alopecia were excluded. We recruited another 63 persons without any malignant or premalignant skin lesions as the control group from the attendees to the clinic for reasons other than skin malignancy. The sampling method was convenient without matching. None of the subjects had received vitamin D supplements.

Primary information including age, sex, professional environment (outdoor/indoor), weekly exposure to sunlight (less than vs more than 6 hours), history of previous SCC, family history of SCC, and smoking status were gathered through self-reported questionnaires and kept confidential throughout the study. Blood samples were drawn and immediately sent to the Razi Hospital laboratory to measure serum levels of 25-hydroxyvitamin $\mathrm{D}_{3}$ (as $\mathrm{ng} / \mathrm{mL}$ ), which is the best available marker for estimating the level of vitamin D in the body. The definitions of $25(\mathrm{OH}) \mathrm{D}$ deficiency $(30 \mathrm{ng} / \mathrm{mL}$ ) were based on the recommendations of the European Endocrine Society [14].

All data were analyzed by SPSS statistical software, and a $P$ value below 0.05 was considered significant. Pearson chisquare and independent sample $\mathrm{T}$ test were applied. Odds ratios (ORs) and $95 \%$ confidence intervals (CIs) were calculated. To counteract the unwanted effect of the confounding variables on the relationship between plasma $25(\mathrm{OH}) \mathrm{D}$ levels and SCC, we utilized the hierarchical multivariate logistic regression models.

\section{Results}

The mean age of the subjects was 50.2 years $(S D=19.01)$; the youngest and oldest patients were 19 and 86 years old, respectively. Characteristics of all patients and controls are shown in Table 1 . The probability of working in the outdoor environment was significantly higher in the SCC group. The SCC patients were significantly more likely to have more prolonged exposure to the sun during the week. Personal history of skin cancer was higher in SCC patients. Regarding the family history of skin cancer and smoking, there was no 
Table 1. Characteristics of Study Subjects

\begin{tabular}{|c|c|c|c|c|c|c|c|}
\hline & \multicolumn{2}{|c|}{ Controls } & \multicolumn{2}{|c|}{ SCC cases } & \multicolumn{2}{|c|}{ Total } & \multirow[b]{2}{*}{ P Value } \\
\hline & No. & $\%$ & No. & $\%$ & No. & $\%$ & \\
\hline \multicolumn{8}{|l|}{ Gender } \\
\hline Male & 23 & 36.5 & 50 & 79.4 & 73 & 57.9 & \multirow{2}{*}{$<0.05$} \\
\hline Female & 40 & 63.5 & 13 & 20.6 & 53 & 42.1 & \\
\hline \multicolumn{8}{|c|}{ Occupational environment } \\
\hline Outdoor & 4 & 6.3 & 25 & 39.7 & 29 & 23 & \multirow{2}{*}{$<0.05$} \\
\hline Indoor & 59 & 93.7 & 38 & 60.3 & 97 & 77 & \\
\hline \multicolumn{8}{|c|}{ Sunlight exposure (weekly) } \\
\hline$>6$ hours & 3 & 4.8 & 25 & 39.7 & 28 & 22.2 & \multirow{2}{*}{$<0.05$} \\
\hline$<6$ hours & 60 & 95.2 & 38 & 60.3 & 98 & 77.8 & \\
\hline \multicolumn{8}{|c|}{ Family history of SCC } \\
\hline Positive & 0 & 0 & 5 & 7.9 & 5 & 4 & \multirow{2}{*}{$>0.05$} \\
\hline Negative & 63 & 100 & 58 & 92.1 & 121 & 96 & \\
\hline \multicolumn{8}{|c|}{ Personal history of SCC } \\
\hline Positive & 0 & 0 & 9 & 14.3 & 9 & 7.1 & \multirow{2}{*}{$<0.05$} \\
\hline Negative & 63 & 100 & 54 & 85.7 & 117 & 92.9 & \\
\hline \multicolumn{8}{|l|}{ Smoking } \\
\hline Yes & 18 & 28.6 & 17 & 27 & 35 & 27.8 & \multirow{2}{*}{$>0.05$} \\
\hline No & 45 & 71.4 & 46 & 73 & 91 & 72.2 & \\
\hline Total & 63 & 50 & 63 & 50 & 126 & 100 & \\
\hline
\end{tabular}

statistically significant difference between patients and controls $(\mathrm{P}$ value $>0.05)$.

In the SCC group, 10 (15.9\%), 9 (14.3\%), and 44 (69.8\%) were in deficiency, insufficiency, and sufficiency of vitamin D, respectively. In the control group, $32(50.8 \%)$ had deficient, $11(17.5 \%)$ had insufficient, and $20(31.7 \%)$ had sufficient levels of vitamin $\mathrm{D}$. These differences are statistically significant $(\mathrm{P}<0.001)$. However, when looking at the quantitative variables, the mean $25(\mathrm{OH}) \mathrm{D}$ level in the total sample was $33.66 \mathrm{ng} / \mathrm{mL}(\mathrm{SD}=24.02)$. Mean vitamin D levels were significantly higher in patients with SCC than in the control group (40.99 ng/mL vs $26.34 \mathrm{ng} / \mathrm{mL}, \mathrm{P}<0.01$ ). As shown in Table 2, the average vitamin D levels had no statistically significant difference among subjects with regard to gender, personal family history of skin cancer, and smoking. However, the average vitamin D level was higher among the people who worked outdoors (such as farmers) than those who worked in closed environments $(44.04 \mathrm{ng} / \mathrm{mL}$ vs $30.56 \mathrm{ng} / \mathrm{mL}, \mathrm{P}=$ $0.008)$. People with prolonged contact with sunlight $(>6$ hours/week) had higher average levels of vitamin D (48.82 $\mathrm{ng} / \mathrm{mL}$ vs $29.33 \mathrm{ng} / \mathrm{mL}, \mathrm{P}=0.000)$. As well, the average vitamin D levels among different age groups had a significant variation such that in the age group 67-86 years they were greater than in other groups, and in the age group 19-33 years average vitamin D levels were the lowest.
As shown in Table 3, based on the results of logistic regression analysis, when $25(\mathrm{OH}) \mathrm{D}$ level was treated as a continuous variable, each unit increase in vitamin D corresponded with a $2.9 \%$ increase in the chance of the occurrence of SCC $($ Wald $=10.55, \mathrm{P}$ value $=0.001)$. The OR in this model for each level of vitamin D was approximately 1.03, or merely 1 unit increase equals a 1.03-time rise in the chance of SCC.

However, after adjusting for the effect of other variablesgender, age, work environment, prolonged sun exposure, personal history of skin cancer-vitamin D levels could not significantly predict the occurrence of SCC (Wald $=3.37, \mathrm{P}$ value $=0.066)$, although an inverse association was found $(\mathrm{B}=-6.3 \%)$.

\section{Discussion}

In this study, without controlling for the effect of undesired variables (including age, sex, and sunlight exposure), an increased level of $25(\mathrm{OH}) \mathrm{D}$ was associated with the risk of SCC. However, after controlling for this effect by using statistical methods, there was no significant relationship between SCC risk and vitamin D level.

We found that the prevalence of SCC was higher in people who worked in an open area (such as farmers and construction workers) and also with more prolonged contact with sunlight, compared with people who worked in closed 
environments or who had shorter contact with sunlight (respectively, $\mathrm{OR}=9.7$ and $\mathrm{OR}=13.16$, P value $<0.05$ ). Thus prolonged exposure to sunlight for any activity-including work, sport, and entertainment-greater than 6 hours per week was defined as a potent risk factor for being diagnosed with SCC. This finding is consistent with the results of many studies showing that the UV beams of sunlight exposure are a known risk factor for SCC, causing mutations in genes that inhibit carcinogenesis $[3,15]$.

The average level of $25(\mathrm{OH}) \mathrm{D}$ in SCC patients was more than that in the control group and was statistically significant (40.99 vs 26.34 , P value < 0.05 ). The unadjusted model of multivariate logistic regression analysis showed a meaningful positive relationship between vitamin $\mathrm{D}$ level and the occurrence of SCC (Table 3). Afzal et al also published similar results; he and his colleagues assessed the relationship of vitamin D and incident SCC in a 28-year prospective study of 10,160 white Danish people and showed a positive association [16]. Eide et al reported similar findings among 3,223 people in the United States in a prospective study [9]. In Brazil, with a high percentage of vitamin D deficiency and insufficiency resembling that in Iran, the level of vitamin D was higher among those with nonmelanoma skin cancers compared with healthy individuals [17]. Liang and colleagues reported analogous results among Chinese women; they found a significantly positive association between plasma $25(\mathrm{OH})$ D levels and SCC risk after adjusting for age at blood draw, season of blood draw, hair dye, burning tendency, the number of sunburns, and UVB flux of residence at blood collection (P for trend = 0.0002) [18]. Conversely, Van der Pols et al, in a prospective study for 11 years in an Australian subtropical community, following baseline assessment of serum $25(\mathrm{OH})$ $\mathrm{D}$ in 1,191 adults, claimed that SCC incidence tended to be lower in those with higher serum levels of $25(\mathrm{OH}) \mathrm{D}(\mathrm{OR}=$ $0.67,95 \%$ CI: 0.44-1.03, P=0.07) [10]. Tang et al seemingly suggested the inverse association between vitamin $\mathrm{D}$ and the risk of nonmelanoma skin cancer among older men [19].

In our study, after adjustment for the effect of possible confounding factors in multivariate logistic regression, vitamin D level could not independently predict the occurrence of SCC. It seems that, as Winsløw et al noted, the level of vitamin $\mathrm{D}$ in our population not consuming supplements is a surrogate for their amount of sun exposure, which per se has an established role in skin cancer [20]. Thus this vitamin
Table 2. Mean Level of 25 OH Vitamin D Within Study Variables

\begin{tabular}{|c|c|c|c|}
\hline & $\begin{array}{c}\text { Mean } \\
(\mathrm{ng} / \mathrm{mL})\end{array}$ & SD & P Value \\
\hline \multicolumn{4}{|l|}{ Gender } \\
\hline Male & 36.63 & 21.69 & \multirow{2}{*}{0.104} \\
\hline Female & 29.58 & 26.58 & \\
\hline \multicolumn{4}{|l|}{ Age group } \\
\hline $15-32$ years & 18.24 & 16.11 & \multirow{4}{*}{0.000} \\
\hline $33-50$ years & 30.56 & 22.99 & \\
\hline $51-63$ years & 38.57 & 22.10 & \\
\hline $64-89$ years & 48.67 & 24.53 & \\
\hline \multicolumn{4}{|c|}{ Occupational environment } \\
\hline Outdoor & 44.04 & 20.05 & \multirow{2}{*}{0.008} \\
\hline Indoor & 30.56 & 24.32 & \\
\hline \multicolumn{4}{|c|}{ Sunlight exposure (weekly) } \\
\hline$>6$ hours & 48.82 & 22.37 & \multirow{2}{*}{0.000} \\
\hline$<6$ hours & 29.33 & 22.78 & \\
\hline \multicolumn{4}{|c|}{ Family history of SCC } \\
\hline Positive & 44.92 & 28.77 & \multirow{2}{*}{0.287} \\
\hline Negative & 33.2 & 23.83 & \\
\hline \multicolumn{4}{|c|}{ Personal history of SCC } \\
\hline Positive & 36.53 & 14.10 & \multirow{2}{*}{0.712} \\
\hline Negative & 33.44 & 24.64 & \\
\hline \multicolumn{4}{|l|}{ Smoking } \\
\hline Yes & 31.35 & 19.88 & \multirow{2}{*}{0.506} \\
\hline No & 34.55 & 25.47 & \\
\hline Total & 33.66 & 24.02 & \\
\hline
\end{tabular}

is not a cause of skin cancer itself. In other words, sunlight exposure, the primary suspect for confounding the conclusions, is responsible for higher vitamin D levels and the higher chance of skin SCC at the same time, especially in those who work outdoors.

The strength of our study was in addressing the effect of confounding factors and moderating their impact on the relationship between vitamin D and SCC. Nevertheless, the most significant limitation was the failure in assessing all possible influencing factors on vitamin D level and the occurrence of SCC such as seasonal changes, ethnicity and race, and skin pigmentation classification.

Table 3. Multivariate Logistic Regression Analysis for the Relationship Between Vitamin D and SCC

\begin{tabular}{|l|c|c|c|c|c|} 
& B & Wald & OR (95\% Cl) & P Value & $\mathbf{R}^{\mathbf{2}}$ \\
\hline Unadjusted model & 0.029 & 10.55 & $\begin{array}{c}1.03 \\
(1.012-1.048)\end{array}$ & 0.001 & 0.104 \\
\hline Adjusted model & -0.063 & 3.37 & $\begin{array}{c}0.939 \\
-0.878-1.004)\end{array}$ & 0.066 & 0.752 \\
\hline
\end{tabular}




\section{Conclusions}

The positive association between vitamin $\mathrm{D}$ and the occurrence of SCC was obscured by modulating the effect of possible confounding factors including age, gender, work environment, and the most important one, sunlight exposure. It is interesting that the relationship was inverse in the adjusted model, although it was not significant. Knowledge about the epidemiology of SCC is very limited in Iran. We recommend further studies, preferably prospective ones with larger sample sizes and addressing all factors that influence both the amount of vitamin $\mathrm{D}$ in the body and the incidence of SCC at the same time.

\section{References}

1. Chinem VP, Miot HA. Epidemiology of basal cell carcinoma. Epidemiologia do carcinoma basocelular [in English, Portuguese]. An Bras Dermatol. 2011;86(2):292-305.

2. Rogers HW, Weinstock MA, Harris AR, et al. Incidence estimate of nonmelanoma skin cancer in the United States, 2006. Arch Dermatol. 2010;146(3):283-287.

3. Reichrath J, Reichrath S. The relevance of the vitamin D endocrine system (VDES) for tumorigenesis, prevention, and treatment of non-melanoma skin cancer (NMSC): present concepts and future perspectives. Dermatoendocrinol. 2013;5(1):38-50.

4. Tongkao-On W, Gordon-Thomson C, Dixon KM, et al. Novel vitamin D compounds and skin cancer prevention. Dermatoendocrinol. 2013;5(1):20-33.

5. Bikle DD. Vitamin D and skin cancer. J Nutr. 2004;134(12 Sup$\mathrm{pl}): 3472 \mathrm{~S}-3478 \mathrm{~S}$.

6. Tuohimaa P, Pukkala E, Scélo G, et al. Does solar exposure, as indicated by the non-melanoma skin cancers, protect from solid cancers: vitamin D as a possible explanation. Eur J Cancer. 2007;43(11):1701-1712.

7. Zeeb H, Greinert R. The role of vitamin D in cancer prevention: does UV protection conflict with the need to raise low levels of vitamin D? Dtsch Arztebl Int. 2010;107(37):638-643.

8. Asgari MM, Tang J, Warton ME, et al. Association of prediagnostic serum vitamin D levels with the development of basal cell carcinoma. J Invest Dermatol. 2010;130(5):1438-1443.
9. Eide MJ, Johnson DA, Jacobsen GR, et al. Vitamin D and nonmelanoma skin cancer in a health maintenance organization cohort. Arch Dermatol. 2011;147(12):1379-1384.

10. van der Pols JC, Russell A, Bauer U, Neale RE, Kimlin MG, Green AC. Vitamin D status and skin cancer risk independent of time outdoors: 11-year prospective study in an Australian community. J Invest Dermatol. 2013;133(3):637-641.

11. Reichrath J, Saternus R, Vogt T. Endocrine actions of vitamin D in skin: relevance for photocarcinogenesis of non-melanoma skin cancer, and beyond. Mol Cell Endocrinol. 2017;453:96-102.

12. Vatandost S, Jahani M, Afshari A, Amiri MR, Heidarimoghadam R, Mohammadi Y. Prevalence of vitamin D deficiency in Iran: a systematic review and meta-analysis. Nutr Health. 2018;24(4):269-278.

13. Khosravi-Boroujeni H, Sarrafzadegan N, Sadeghi M, et al. Prevalence and trends of vitamin D deficiency among Iranian adults: a longitudinal study from 2001-2013. J Nutr Sci Vitaminol (Tokyo). 2017;63(5):284-290.

14. Holick MF, Binkley NC, Bischoff-Ferrari HA, et al. Evaluation, treatment, and prevention of vitamin D deficiency: an endocrine society clinical practice guideline. J Clin Endocrinol Metab. 2011;96(7):1911-1930.

15. Hussein MR. Ultraviolet radiation and skin cancer: molecular mechanisms. J Cutan Pathol. 2005;32(3):191-205.

16. Afzal S, Nordestgaard BG, Bojesen SE. Plasma 25-hydroxyvitamin $\mathrm{D}$ and risk of non-melanoma and melanoma skin cancer: a prospective cohort study. J Invest Dermatol. 2013;133(3):629-636.

17. Soares AM, Szejnfeld VL, Enokihara MY, Michalany N, Castro $\mathrm{CH}$. High serum 25-hydroxyvitamin D concentration in patients with a recent diagnosis of non-melanoma skin cancer: a case-control study. Eur J Dermatol. 2018;28(5):649-653.

18. Liang G, Nan H, Qureshi AA, Han J. Pre-diagnostic plasma 25-hydroxyvitamin D levels and risk of non-melanoma skin cancer in women. PLoS One. 2012;7(4):e35211.

19. Tang JY, Parimi N, Wu A, et al. Inverse association between serum 25(OH) vitamin D levels and non-melanoma skin cancer in elderly men. Cancer Causes Control. 2010;21(3):387-391.

20. Winsløw UC, Nordestgaard BG, Afzal S. High plasma 25-hydroxyvitamin $\mathrm{D}$ and high risk of nonmelanoma skin cancer: a Mendelian randomization study of 97849 individuals. $\mathrm{Br} J$ Dermatol. 2018;178(6):1388-1395. 